\title{
Mycofabrication of Silver Oxide Nanoparticles Derived from Aspergillus Terreus FC36AY1 and its Potent Antimicrobial, Antioxidant, and Anti- Angiogenesis Activities
}

\section{Manon Mani Vellingiri}

RVS Educational Trust: Rathinavel Subramaniam Educational Trust

Mithu Ashwin John Kennedy

Pasteur Institute of India

Parimala Gnana Soundari Arockiam Jeyasundar

Gandhigram Rural Institute: The Gandhigram Rural Institute Deemed University

Swamiappan Sathiskumar

Bharathiar University

Ulaganathan Priyadharshini

Bharathiar University

Paramasivam Deepak

Dr NGP Arts and Science College

Wen-chao Liu

Guangdong Ocean University

Balamuralikrishnan Balasubramanian ( $\sim$ geneticsmurali@gmail.com )

Sejong University

\section{Research Article}

Keywords: Angiogenesis, antimicrobial, antioxidant, Aspergillus terreus, HET-CAM, silver oxide nanoparticles.

Posted Date: August 18th, 2021

DOl: https://doi.org/10.21203/rs.3.rs-735114/v1

License: (9) (1) This work is licensed under a Creative Commons Attribution 4.0 International License. Read Full License 


\section{Abstract}

The present study focused to synthesize the silver oxide nanoparticles (AgONPs) from endophytic fungus, as the strain eventually possess the medicinal property acquired from the medicinal tree, Aegle marmelos. About 35 pigmented endophytic fungi were isolated, screened for antagonistic activity against 12 clinical human pathogens and antioxidant activity through DPPH radical scavenging assay; among the isolates, FC36AY1 explored the highest activity. The endophytic fungus was identified as Aspergillus terreus FC36AY1 through microscopic and Internal Transcribed Spacer (ITS) 1, ITS 4 and 18S rRNA amplification. The AgONPs were synthesized from the strain FC36AY1 and characterized for its confirmation, functional groups, nanostructures with unit cell dimensions, size and shape, presence of elements through UV-Vis spectrophotometry, FT-IR, X-Ray Diffraction, Scanning Electron Microscopic with EDX analysis. The myco-generated AgONPs manifested their antimicrobial and antioxidant properties with maximum activity at minimum concentration. Moreover, the inhibition of angiogenesis by the AgONPs in Hen's Egg Test on the Chorio-Allantoic Membrane analysis evinced significant bioactivity at least concentration. Thus the results of this investigation revealed that this bioactive fungal mediated AgONPs can be exploited as potential in biomedical applications.

\section{Introduction}

Nanotechnology is a growing field mainly in the development of nanomedicines with various sizes, morphology, chemical compositions and those are the escalating ones in treating various diseases in the medicinal fields. The nanoparticles could be synthesized by physical/substantial, chemical/synthetic or hybrid ones with two or more methods. The physical and chemical synthesis were popular methods but the usage of chemicals in the synthesis limits the nanoparticle applications in the medicinal field. The chemicals hydrazine hydrate [1], sodium borohydride [2], potassium borohydride [3], and methoxy polyethylene glycol [4] are used in the chemical reduction methods and these create toxic on the surface of the nanoparticles and thus brings out larger issues in the clinical trials. To prevent the toxicity of nanoparticles, an alternate method is the green synthesis of nanoparticles (NPs) which is an eco-friendly and relevant with the pragmatic choice of medical applications [5]. This green protocol yields the stable NPs in an inexpensive method and carried out using plants, algae, yeasts, fungi, actinomycetes and bacteria. The green synthesis is a significant method involved in the synthesis of natural NPs which does not cause any adverse effects in clinical trials. The process of NPs biosynthesis is significantly a reduction process where the bacteria or fungi which are found to be electrochemically active are efficient in a metal reduction under a wide extensions of natural conditions [6]. Moreover, the microbes can also produce NPs as a by-product of their respiration or metabolic reactions. The microbes produce the NPs intracellular and extracellular mechanism where maximum NPs are retrieved from the extracellular production [5].

The silver oxide nanoparticles (AgONPs) have distinctive physical, chemical, electrical and optical properties that are being integrated into products or by-products ranging from photovoltaic systems to biological materials and chemical applications for their inflated solidity, low dregging temperatures, and 
electrical conductivity. The production of the AgONPs from microbial explores the great interest towards the precipitation by the reduction process due to its metabolic activity. There are some bacterial genera, like Arthrobacter, Pseudomonas, Bacillus and Escherichia synthesis of AgONPs by their metabolic activity induction by the stimulation of commercial precursors [7]. On comparison with bacteria, fungi were found to produce the maximum of NPs quantitatively in extracellular metabolic mechanism because fungi mycelial structures could withstand the agitation and flow pressure in bioreactors or other culture chambers. Moreover, fungi are having rapid growth with maximal bioactive products, uncomplicated handling and easy in synthesizing NPs [8, 9]. The synthesis of AgNPs by various fungi through extracellular mechanism was reported by many researchers. Ahmad et al [10] reported production of $\mathrm{Ag}^{+}$ ions has materialized by reduction process through the liberation of reductases in Fusarium oxysporum. Penicillium fellutanum (marine fungal isolate) which was isolated from mangrove sedimental area of South India near coastal regions and this fungus synthesized AgNPs [11] also Trichoderma viride, a fungus that is non-pathogenic synthesized the AgNPs [12]. A report of Ishida et al [13] explored the synthesis of AgNPs from a phytopathogenic fungus, Fusarium oxysporum by the extracellular process. Further, the investigation of Ishida et al. [13] manifested reduction of metal ions are due to the reductases released by the working fungus and thus makes an in-vitro generation of AgNPs using cell extract-based process possible. Recently, Neethu et al [5] synthesized AgNPs by the reduction process occurred through enzymatic reaction of silver nitrate, a commercial source in the marine algicolous endophytic fungus Penicillium polonicum and applied as antimicrobial coatings on medical devices for the prevention of microbial growth. The potentiality of anti-cancer nanoparticles exhibited its activity on a varied type of human cancer cells. Few researchers myco synthesized the AgNPs and explored its anti-cancer activity in opposition to HeLa cells lines and MCF-7 cell lines [14-16].

With the increasing demands on the antimicrobials (antibiotics), antioxidants (anti-ageing), anti-cancer agents and the expensive cost in the development of these products has pushed the researchers to develop the effective and novel bioactive products from advanced technology [17]. The AgONPs produced from the endophytic fungi would eventually possess the medicinal property because the endophyte resides inside the medicinal tree mimic the same metabolism as the tree does without causing any diseases. The endophytic fungal strain is an exceptionally fascinating origin of producing the bioactive novel secondary metabolites possessing the biological properties with greater impact $[16,18]$. According to the myco-research, only limited endophytic fungal strains isolated have been reported to synthesize AgNPs [16, 19-22]. Till date, the exploration on the extracellular synthesis of AgONPs by the fungal endophytes has not yet completed mainly in the Western Ghats clusters. Hence, the current study aimed to isolate the endophytic fungi from Aegle marmelos (Vilva) around the Western Ghats and to assess the antimicrobial, antioxidant and anti-angiogenic properties of AgONPs synthesized from Aspergillus terreus.

\section{Materials And Methods:}

\subsection{Isolation and screening of endophytic fungi}


The tree samples were collected from A. marmelos collected near the foothills of Marudhamalai [Coimbatore, Tamil Nadu, India $\left(11.0183^{\circ} \mathrm{N}, 76.9725^{\circ} \mathrm{E}\right)$ ] by the authorization of the local tribal people. Three different sections were selected from each tree such as stem, branch and leaf. Each section was taken for 3 different segmentation and therefore the samples were placed in Sabouraud's Dextrose Agar (SDA), Potato Dextrose Agar (PDA) and Malt Extract Agar (MEA) media. The samples were collected and surface sterilized by following the method of Mani et al. [23]. The endophytic fungi isolated were taken for antagonism screening by cross- streak method [24]. The pathogens (Obtained from MTCC, Chandigarh and PSG Hospitals, Coimbatore, TN, India as stated in previous studies [25]) used in this study were Staphylococcus aureus MTCC 3103, Shigella sp., Staphylococcus epidermidis, Pseudomonas aeruginosa MTCC 1688, Enterococcus faecalis MTCC 2729, Bacillus subtilis, Escherichia coli MTCC 294, Proteus mirabilis MTCC 425, Klebsiella pneumoniae, Salmonella typhi MTCC 531, Candida albicans MTCC 183 and Aspergillus niger were taken for studies. The pathogens were selected based on common infections caused in human beings especially gastric and skin infections. Moreover, the isolated 35 pigmented endophytic fungi were screened for antioxidant potentiality through DPPH radical scavenging assay as per the statement of Yildrim et al [26] in two different concentrations such as 50 and $100 \mu \mathrm{g} / \mathrm{mL}$ of crude extract.

\subsection{Identification and characterization of endophytic fungus}

The antagonistic and antioxidant potential endophytic fungus was identified by microscopic and molecular analysis. The strains were viewed through lactophenol cotton blue staining [27] and examined at 400x and 1000x light microscopy. The morphology of prospective endophytic fungal spores (aerial and substrate mycelia, and arrangement of spores either in chain form or interlinked) were assessed by inoculating on SDA, PDA, and MEA media poured onto coverslips and viewed at 1000x magnification after incubation period at $28 \pm 2^{\circ} \mathrm{C}$ of $4-7$ days. The molecular identification was analyzed by the ITS1, $5.8 \mathrm{~s}$ and ITS4 amplification of rDNA. The specific PCR primers were used for the amplification of determining 18S rRNA sequence analysis. Endophytic rDNA fragments were specific and specialized primers that was operated to vindicate the morphospecies of divergent kind of mycelia $[28,29]$. The ITS sequences were deposited with NCBI gene bank and the accession number was retrieved. Phylogenetic tree were constructed from the aligned sequences using neighbor-joining $(\mathrm{NJ})$ method with 100 bootstrap replications were performed using CLC Main workbench 8.

\subsection{Synthesis of AgONPs}

The endophytic fungus was allowed to dwell in a Minimal media consisting of preferred carbon (C) and nitrogen $(\mathrm{N})$ source and incubated for 36 hours at $27 \pm 2 \mathrm{C}$. The FC36AY1 was screened for growth and production of AgONPs in wide range of $\mathrm{pH}(5,6,7,8,9)$ and silver nitrate (precursor) $(0.1 \mathrm{M}, 0.01 \mathrm{M}, 0.001$ $\mathrm{M})$. The strain was taken for synthesis on the basis of resistance exhibited through $\mathrm{pH}$ and varied concentration of silver nitrate. The optimized $\mathrm{pH}$ and the $\mathrm{AgNO}_{3}$ concentration for the microbial synthesis of nanoparticles were 7.2 and $0.1 \mathrm{M}$ respectively. After incubation, a known quantity of $0.1 \mathrm{M}$ silver nitrate 
$\left(\mathrm{AgNO}_{3}\right)$ was added to the culture filtrate of the media. After 12-48 $\mathrm{h}$, the culture media were observed for change of brown colour in the flask which indicated the formation of AgONPs. The brown coloured solution was separated by filtration, centrifuged at $10000 \mathrm{rpm}$ for $30 \mathrm{mins}$, washed, dried at $300^{\circ} \mathrm{C}$ in a muffle furnace and used for further studies.

\subsection{Characterization of AgONPs}

The AgONPs were characterized through UV-Vis spectrometry, SEM (Scanning Electron Microscope), FTIR (Fourier transform Infra-Red) spectroscopy, X-ray diffraction (XRD) and Energy Dispersive Analysis (EDX). The UV-visible spectrum was recorded from 300 to $700 \mathrm{~nm}$ wavelength at room temperature with Double beam spectrophotometer (Hitachi, Japan). The reaction blank was double sterile distilled water. The FT-IR spectroscopic analysis was carried out in the instrument FT-IR spectrometer (Nicolet Avathar spectrometer - 320; Nicolet Instruments, Madison) at a scan range and scanning speed of $4000-400 \mathrm{~cm}^{-}$

1 and $2 \mathrm{~mm} \mathrm{~s}^{-1}$ respectively. Dried sample was treated with $\mathrm{KBr}$, a special grade for pelleting in the ratio 1:50 and were used for the FT-IR analysis. An X-ray diffraction study of AgONPs was performed using an X-ray diffractometer (X'Pert-PRO) with a horizontal goniometer. The elevated resolution on XRD patterns was measured with $\mathrm{Cu}$ target at $3 \mathrm{KW}$ and a scintillation counter $(\mathrm{k}=1.5406 \backslash \mathrm{AA})$ at $40 \mathrm{kV}$ and recorded at $30 \mathrm{~mA}$ in the range of 2 Theta $=10^{\circ}$ to $90^{\circ}$. The size and shape of the synthesized AgONPs were analyzed (SEM-Quanta-250-FEG, USA). EDX analysis was performed to detect the presence of elements through EDX -Coupled with SEM-Quanta-250-FEG, USA.

\subsection{Assessment of antimicrobial activity}

The antimicrobial activity was assessed by well diffusion method [30] using Muller Hinton Agar medium. A total of 12 different clinical pathogens such as K. pneumoniae, S. aureus, P. aeruginosa, S. epidermidis, E. faecalis, E. coli, P. mirabilis, B. subtilis, S. typhi, Shigella sp, C. albicans and A. nigerwere taken for the inhibition of pathogenic growth by the synthesized AgONPs $(500 \mu \mathrm{g} / \mathrm{ml})$. The plates with bacterial and fungal pathogenic strains were incubated at $37^{\circ} \mathrm{C}$ for $18 \mathrm{~h}$ and $28^{\circ} \mathrm{C}$ for $36 \mathrm{~h}$ respectively. After incubation, the plates were measured for the inhibition zones around each well indicating the antibacterial and antifungal activity.

\subsection{Determination of antioxidant properties 2.6.1. DPPH radical scavenging assay}

The antioxidants contained in AgONPs were prepared into sequential concentrations $(20-100 \mu \mathrm{g} / \mathrm{ml})$ to determine AgONPs potentiality for scavenging activity of commercial oxidant: 2, 2-diphenyl-1picrylhydrazyl (DPPH) radicals using the method of Yildrim et al [26] in triplicates. Different concentrations of the sample AgONPs were dispensed into separate test tubes and made up to $1 \mathrm{~mL}$. About $3 \mathrm{~mL}$ of DPPH mixture (1 mM DPPH commercial radical solution in 95\% methanol) were put into the AgONPs added respective tubes, vortexed, and subsequently incubated for 25-30 min in the dark at room temperature. After incubation time, the samples measured for absorbance at $\lambda=517 \mathrm{~nm}$ and $1 \mathrm{~mL}$ of $95 \%$ methanol was used as a control. The antioxidant activity is given as a percentage (\%) and was 
evaluated using the standard formula: [(ctrl absorbance - ext absorbance) / (ctrl absorbance) $\times 100]$ - (ctrl: control; ext: extract).

\subsubsection{Metal chelation assay}

The estimation of chelation effect on ferrous ions were carried out with the method of Dinis et al. [31]. Various concentrations of AgONPs were taken in test tubes (as in Sect. 2.6.1) and made upto $0.5 \mathrm{~mL}$. About $0.5 \mathrm{~mL}$ of Ferrous Sulphate- $\mathrm{FeSO}_{4}(0.12 \mathrm{mM})$, and $0.5 \mathrm{~mL}$ of Ferrozine (3-[2-Pyridyl]-5, 6-diphenyl1, 2, 4-triazine-4, 4'-disulfonic acid Na-salt: $0.6 \mathrm{mM}$ ) were added to the test tubes containing the samples. The tubes were vortexed and kept still at room temperature (RT) for 10 mins. The absorbance was read at $562 \mathrm{~nm}$ after 10 mins in UV-Vis Spectrophotometer. The ability of the sample where it bind or chelate ferrous $\left(\mathrm{Fe}^{+}\right)$ion(s) was estimated using the control components through the formula: Ferrous ion chelating ability $(\%)=[($ ctrl absorbance - ext absorbance $) /($ ctrl absorbance $) \times 100]$ - (ctrl: control; ext: extract).

\subsubsection{Superoxide Anion Radical Scavenging assay}

The superoxide anion radical- $\left(\mathrm{O}^{2-}\right)$ scavenging capacity of the AgONPs was measured according to the method described by Liu et al. [32] using a minor modification [33]. The radicals of superoxide are initiated with the combination of PMS (phenazine methosulphate) - NADH (nicotinamide adenine dinucleotide) systems by the creation of oxidation due to NADH and reduction by NBT (nitroblue tetrazolium). In this assessment, the superoxide free radicals were produced in $1.0 \mathrm{~mL}$ of $50 \mu \mathrm{M}$ NBT present in three $\mathrm{mL}$ of $(16 \mathrm{mM})$ Tris- $\mathrm{HCl}$ buffer with $\mathrm{pH} 8.0$ after then addition of one $\mathrm{mL} 78 \mu \mathrm{M}$ NADH solution which creates the oxidation. Then the samples AgONPs in different concentrations (20 to 100 $\mu \mathrm{g} / \mathrm{mL}$ ) were put on to the above prepared mixture in separate test tubes and the samples were dissolved in methanol. The control tube was kept with methanol. Then, the reaction was instigated by the addition of one $\mathrm{mL}$ of $10 \mu \mathrm{M}$ phenazine methosulphate (PMS) solution to the mixture, mixed well and kept still at RT for 2 mins. The absorbance were read at $560 \mathrm{~nm}$. The standard component was ascorbic acid. The scavenging activity of AgONPs was determined by: [(ctrl absorbance - ext absorbance) / (ctrl absorbance) × 100]- (ctrl: control; ext: extract).

\subsubsection{Nitric oxide scavenging assay}

The scavenging activity of nitric oxide $\left(\mathrm{NO}^{2-}\right)$ radicals were assessed by the method of Sreejayan et al. [34]. The stable products of nitric oxide are nitrite and nitrate in which the free nitric oxide radicals joins with oxygen atom to produce stable products. The reduced form of nitrite was due to the competition of oxygen in nitric oxide molecule by the scavengers, and thus the nitrite concentration in aqueous matter was determined with the addition of Griess reagent through spectrophotometrically (546 nm), where the nitrite reforms into a stable product. The generation of nitric oxide radicals were acheivedby the addition of one $\mathrm{ml}$ of $10 \mathrm{mM}$ sodium nitroprusside. Then, the samples prepared at various concentrations (as in Sect. 2.6.1) were added in phosphate buffer with $\mathrm{pH}$ 7.4. The mixture was vortexed and kept at $25^{\circ} \mathrm{C}$ for 2 hours 30 mins. After incubation time, about $1 \mathrm{ml}$ of Greiss reagent (mixture of $1 \%$ sulphanilamide, $2 \%$ orthophosphoric acid and $0.1 \%$ NEDD- naphthyl ethylene diamine dihydrochloride) was put on to the 
respective test tubes, mixed well and immediately the absorbance was estimated at $546 \mathrm{~nm}$. The percentage inhibition of free radicals by AgONPs was calculated using the formula: Chelating ability (\%) $=[($ ctrl absorbance - ext absorbance) $/$ (ctrl absorbance $) \times 100]-($ ctrl: control; ext: extract) .

\subsection{Determination of anti-angiogenesis through HET-CAM (Hen's Egg Test on the Chorio-Allantoic Membrane)}

This determination is executed to understand the inflammatory tissue reactions of bioactive compounds or synthesized bio-nanoparticles on the growing tissues and blood vessels and this was determined by direct evaluation method [24]. The embryonated eggs of 9th day incubation were taken for this assessment; each egg were mounted on the working table/ for further process and the eggs of Chittagong breed were purchased from K. A. Poultry Farm (Tiruppur, TN, India). The air space area of the egg was kept facing upwards and using sterile blade a small incision was made on the shell. The shell and capsular membrane was then removed, and the prepared AgONPs $(200 \mu \mathrm{L})$ on small discs in triplicates was carefully inserted into the CAM space. Before placing the sample(s) the number of blood vessels were counted and after the stipulated 2 and 18 hours the angiogenic process was evaluated in each egg. $0.1 \mathrm{~N} \mathrm{NaOH}$ (positive control) and $0.9 \% \mathrm{NaCl}$ (negative control). Each control and sample were added to embryonated eggs in triplicates and assessed.

\subsection{Statistical analysis}

The results of antimicrobial, antioxidant and anti-angiogenic activity are given as mean \pm SD (standard deviation) and assessed using one- way ANOVA, exhibiting p-value of 0.05 being significant, by the (Graph Pad Prism 8.0) statistical software.

\section{Results And Discussion}

\subsection{Isolation and screening of endophytic fungi from Vilva tree}

Several bioactive metabolites had been produced by endophytic fungi were reported as antibiotic compounds exhibiting a wide range of antagonistic spectrum against Gram-positive and Gram-negative bacteria. Mostly the pigmented fungi contain more bioactivity than non-pigmented ones [35] and this eventually led this research to isolate the pigmented strains. The pigmented endophytic fungal isolates were preliminarily investigated for their antagonistic activity (Table S1 and S2) and among 35 strains, 5 endophytic fungi FC25BYI, FC36AY1, FC39BBr, FC3ABr and FC32AGr exhibited highest inhibitory activity against maximum pathogens tested and the most prominent potential fungus which ranked first in maximum activity (FC36AY1). Further, the results of antioxidant activity explored the highest activity in the crude extract of several isolated endophytes and among the isolates, FC36AY1 explored the maximum activity in a dosage-dependent approach. The crude extract has been extracted using six different polar and non-polar solvents in a gradient. The initiation or spawning of free radicals in human body may be due to normal or pathological metabolism in cell. Oxidation was more vital to the organisms 
like plants, animals, human beings and microorganisms for energy production which acts as fuel in several biological processes during metabolism. Nevertheless, the uncurbed production of oxygen-derived free radicals mainly implicates at the beginning of several diseases such as onco- related disease: cancer, ageing, etc [36, 37]. The microbe FC36AY1 can scavenge the free radicals at least concentration.

\subsection{Identification and characterization of endophytic fungi}

The spore morphology of the isolate FC36AY1 exhibited distinctive colony morphology and the microscopic attributes like aerial and substrate mycelial interlinked hyphae and spore structure and their arrangements which were identified at the level of genus. The fungus produced yellow to brown coloured mycelial structures (aerial mycelium: yellow coloured; substrate mycelium: brown coloured) with yellow diffusible pigments in SDA (Fig. 1). The strain FC36AY1 was brightly visible under Lactophenol cotton blue staining. The hyphae are septate and hyaline (Fig. 1b); Conidiophores are smooth-walled and hyaline, long, terminating in mostly globose vesicles (Fig. 1C). The conidia of Aspergillus species are tiny of $2 \mathrm{~mm}$ in diameter, globose - shaped, sessile and hyaline (Fig. 1d) [38, 39]. The strain belongs to the Order Eurotiales, family: Trichocomaceae.

The search of novel secondary metabolites hidden in the important genetic resource are endophytic fungi [23]. The endophytic fungus was identified at genus level and molecular characterization were determined based on sequencing the ITS1-5.8S-ITS4 region. The amplification of ITS rDNA region of the potential endophyte FC36AY1 were sequenced and compared with the other organisms' ITS sequences using BLAST explored in the NCBI database and the generation of phylogenetic tree (Fig. 2) was done by connecting this strain to their closely associated fungal strains by Neighborhood Joining $(\mathrm{NJ})$ plot. The alignment and bootstrapping of the sequences were determined by CLUSTAL $X$; the sequences that revealed $\mathrm{E}=0.0$ and highest $\%$ similarity with the amplified sequences were taken for alignment process. The identified organism was Aspergillus terreus. The NCBI accession ID for isolated strain Aspergillus terreus FC36AY1 as KY807648.

\subsection{Synthesis and characterization of AgONPs from FC36AY1}

The fungus was exposed to $\mathrm{AgNO}_{3}$ and on incubation time, the fungus exhibited the formation of AgONPs on the exterior of the cell wall by the colour alteration from straw yellow to brown color at the $\mathrm{pH}$ 7.2. It indicated the development of the NPs might be due to the extracellular oxidase enzymes or biomolecules synthesis when the fungus was cultured in the silver nitrate solution. The AgONPs are separated by the centrifugation process and dried. The origination of nanoparticles and its stability is greatly influenced in the medium by the $\mathrm{pH}$ and temperature $[35,40,41]$. About $124 \mathrm{mg} / \mathrm{L}(124 \mathrm{ppm})$ of AgONPs were synthesized from $A$. terreus in $100 \mathrm{mM}$ concentration of silver nitrate. This was akin to the results of Balakumaran et al. [16] where about 214 ppm of AgONPs were synthesized from A. terreus 1 $\mathrm{mM}$ concentration. The NPs can be synthesized from both intracellular and extracellular synthesis but more quantity of NPs were retrieved from extracellular synthesis. This extracellular was found to be most 
significant and extensively used hence no strategies are necessary to untie the NPs from the cells [4245]. The three key factors which are significant in the synthesis of AgNPs are reducing agent, reaction medium [46] and the synthesis is enhanced by enzyme-catalyzed reaction [47]. The morphology and size of the AgONPs may change due to the conformational derivation and revamp in the nitrate reduction enzymes in the fungal culture filtrate which is caused by various effects in proton concentration [48]. Deepak et al. [49] disclosed the condition of the AgNPs myco-fabrication was alkaline, the synthesis would be rapid than in acidic circumstances. Simply this can meant, synthesis boosts up when the $\mathrm{pH}$ escalates respecting the alkaline zone. Nevertheless, these nanoparticle dispersed in the culture medium must be filtered to annihilate fungal remnants and impurities, which could be done in various techniques employed for filtration processes such as simple filtration, gel filtration, membrane filtration, ultracentrifugation, and dialysis [50-52].

The UV-Vis spectral analysis confirmed the existence of AgONPs (Fig. 3a). The peak formed at $421 \mathrm{~nm}$ explored the specificity of AgONPs and there was no additional increase in intensity implicating the absolute reduction of silver ions [53]. The AgONPs ranged in between 400 to $450 \mathrm{~nm}$ indicated the presence of larger NPs [54]. According to a few types of research, the NADH-dependent nitrate reductase enzyme is more needed for the silver ions for the reduction process and this enzyme was produced by the fungus extracellularly. The reduction process succeeded on the surface of the cell wall where the enzymes were available by a nitrate-dependent reductase. Further few extracellular enzymes such as anthraquinones and acenaphthoquinone act as an electron shuttle in the reduction of silver [55]. The investigation report of Sunkar and Nachiyar [56] revealed that the AgNPs absorption peak at 400 and 423 $\mathrm{nm}$ synthesized by endophytic fungal strains Garcinia xanthochymus and Aravae lanata.

The XRD pattern of AgONPs synthesized using A. terreus FC36AY1 explicated the crystalline nature and displaying the structural information (Fig. $3 b$ ). The XRD spectrum of the sample indicated two diffraction peaks at $27.28^{\circ}$ and $31.75^{\circ}$, which corresponds to (110) and (111) of $\mathrm{Ag}_{2} \mathrm{O}$. Besides, the diffraction peaks at $45.74^{\circ}, 54.36^{\circ}$ and $66.9^{\circ}$ can be indexed to (211), (220) and (222) planes of face-center cubic (fcc) silver, respectively. These peaks matched with the standard $\mathrm{Ag}_{2} \mathrm{O}$ (JCPDS 76-1393). Some other unknown peaks were also observed, which may correspond to fungal pellets. The FT-IR spectra of AgONPs (Fig. 4) and different phases of synthesized AgONPs showed the characteristic bands at 3441.01 denotes the presence of hydroxyl group and an alcohol class of compounds. The stretch at 2968.45 denotes the $\mathrm{C}-\mathrm{H}$ with alkane group and the stretch at 1645.28 and 1631.78 denotes the existence of $\mathrm{C}=\mathrm{C}$ stretching alkene compounds. The presence of NPs associated with proteins can be occurred either by the presence of unbound amine class or cysteine residues and also by the electrostatic magnetism of negative carboxylate groups present in proteins or enzymes [57]. The peak at 1408 represented the presence of $\mathrm{C}=\mathrm{C}$ stretchings and presence of aromatic compounds. The peak at 1384.89 denotes the presence of alkane with $\mathrm{C}-\mathrm{H}$ bonds. The peaks around 1242.16 and 1120.64 denotes the existence of $\mathrm{C}-\mathrm{N}$ stretching amine group and $\mathrm{C}-\mathrm{O}$ stretching secondary alcohol group respectively. The stretching of 1066 denotes the presence of C-O stretches primary alcohol. The presence of alcohols and amines in this current investigation was similar to the research of Vighneshwaran et al [58] [35]. The 
peaks at $983.70,948.98$ and 709.80 denote the presence of $\mathrm{C}=\mathrm{C}$ alkene groups. The peak 538.14 denotes the presence of AgONPs and this is approximately similar to the results of Singh et al. [22]. The protein molecules present in the extracellular enzyme filtrate act as reducing and stabilizing agent by the attachment of unchained amino groups/cysteine remnants or along the electrostatic attraction of carboxylate groups (negative charge) which aids in the binding of AgONPs [22, 57].

The SEM analysis involves important decisions and choices that are unique where the AgONPs are found to be in an irregular spherical shape (Fig. 5a) [60]. The size varies from $60 \mathrm{~nm}$ to $100 \mathrm{~nm}$ in SEM analysis, which denotes the confirmation size of NPs. Moreover, the size of the AgONPs in this study was found to be at $60 \mathrm{~nm}$ which is due to the concentration of silver nitrate at $100 \mathrm{mM}$ [35]. This was similar to the report of Phanjom and Ahmed [61] synthesized the AgNPs from Aspergillus oryzae in varied concentrations of $\mathrm{AgNO}_{3}$ from $1 \mathrm{mM}$ to $10 \mathrm{mM}$. The synthesized NPs sizes were found to be between 7.22 and $17.06 \mathrm{~nm}$ up to the concentration of $8 \mathrm{mM}$, while the size scaled upto 45.93 and $62.12 \mathrm{~nm}$ at the concentrations of $9 \mathrm{mM}$ and $10 \mathrm{mM}$ of $\mathrm{AgNO}_{3}$ respectively. Figure $5 \mathrm{~b}$ explains the presence of silver element and this was elucidated by EDX Analysis. The obtained results of EDX was similar to the investigation report of Balakumaran et al [35]. This was performed to determine the presence of elements in the synthesized particles.

\subsection{Determination of antimicrobial activity}

The antimicrobial assessment for the synthesized AgONPs against stated pathogens. The AgONPs explored antimicrobial activity for all 12 pathogens where the highest activity was recorded at odds of $C$. albicans, A. niger, B. subtilis, E. faecalis, E. coli and S. epidermidis and no activity was noticed against $P$. mirabilis (Table 1). The silver ions from the AgONPs will be deposited as granules and vacuoles into the cell walls; moreover, the cell division would be inhibited with further damage in the cell layered envelope and few cellular components of the bacteria [61-63]. The results were approximately similar to the research of Balakumaran et al [35] where the AgONPs exhibited the antimicrobial activity in the highest manner. Moreover, the AgNPs evinced the maximum activity against most of the Gram-negative clinical pathogens and this correlates with the current investigation. The antibacterial effects of AgNPs in $S$. aureus and E. coli pathogenic strains were noticed in the investigation of Kim et al. [64] and the record of Ninganagouda et al. [65] exhibited the AgNPs synthesized by Aspergillus flavus against E. coli explored the antibacterial activity. Few kinds of research have been conducted explored the antimicrobial activity against various bacterial strains, such as $S$. aureus, Citrobacter sp., Shigella dysenteriae type I, $P$. aeruginosa, E. coli, and B. subtilis [66] and two different fungi Trichophyton mentagrophytes and Candida $\mathrm{sp}[66,67]$. Fatima et al. [68] determined that the antibacterial and antifungal assessment of synthesized AgNPs from A. flavus. Their synthesized AgNPs were effective in suppressing the growth of bacteria Bacillus cereus, B. subtilis, E. coli, Enterobacter aerogenes, and co- culturing of $S$. aureus, along with $E$. coli and $B$. subtilis being most sensitive. This particular antimicrobial assessment was dose-dependent, where the maximized results obtained by the preparation of NPs in combination with the tetracycline, in preference on their own [68]. The research of Gudikandula et al. [44] stated the inhibition of bacterial 
growth is directed by the NPs, which causes progressive metabolic responses by contacting the cell wall, with the production of ROS. Therefore, the antimicrobial AgNPs disrupts the cell membrane enabling a higher degree of reciprocity with the bacterial cell membrane, emanating in the bacterial death $[5,69]$.

Table 1

Determination of antimicrobial activity of AgONPs derived from Aspergillus terreus FC36AY1

\begin{tabular}{|lll|}
\hline S. No. & Pathogens & Zone of Inhibition (in cm) \\
\cline { 3 - 3 } & & AgONP's \\
\hline 1 & Staphylococcus aureus & $1.3 \pm 0.06$ \\
\hline 3 & Klebsiella pnuemoniae & $1.5 \pm 0.06$ \\
\hline 4 & Staphylococcus epidermidis & $1.85 \pm 0.05$ \\
\hline 5 & Pseudomonas aeruginosa & $1.15 \pm 0.05$ \\
\hline 6 & Enterococcus faecalis & $2.1 \pm 0.1$ \\
\hline 7 & Bacillus subtilis & $2.05 \pm 0.05$ \\
\hline 8 & Escherichia coli & $1.9 \pm 0.05$ \\
\hline 9 & Proteus mirabilis & $0.17 \pm 0.29$ \\
\hline 10 & Shigella sp & $1.02 \pm 0.1$ \\
\hline 11 & Salmonella typhi & $0.88 \pm 0.08$ \\
\hline 12 & Candida albicans & $2.18 \pm 0.03$ \\
\hline Zone Mesurement of inhibition zone was computed in centimeter \pm standard deviation (SD) of three \\
independent experiments- triplicates; (-) no activity.
\end{tabular}


Table 2

Anti-angiogenesis effect of AgONP's in HET-CAM analysis

For 2 hours

No. of vessels in

untreated CAM
No. of vessels in treated CAM
For 18 hours

$\begin{array}{ll}\begin{array}{ll}\text { No. of } \\ \text { vessels }\end{array} & \begin{array}{l}\text { No. of } \\ \text { vessels }\end{array} \\ \text { in untreated } & \begin{array}{l}\text { in treated } \\ \text { CAM }\end{array} \\ \text { CAM }\end{array}$

\begin{tabular}{lcccl}
$\begin{array}{l}\text { Negative Control - } \\
\text { NaCl }\end{array}$ & $17.67 \pm 0.6$ & $16.67 \pm 0.6$ & $17.67 \pm 0.6$ & $14.67 \pm$ \\
$\begin{array}{l}\text { Sample }-1-200 \mu l \\
\text { AgONP's }\end{array}$ & 12 & $7.67 \pm 0.6$ & 12 & $3.63 \pm 0.6$ \\
\hline
\end{tabular}

Positive control -

$10.67 \pm 0.6$

9

$10.67 \pm 0.6$

$5.67 \pm 0.6$

Mean values of triplicates with standard deviation.

\subsection{Assessment of antioxidant activity}

The antioxidant activity for the synthesized AgONPs was performed through DPPH, superoxide, nitric oxide radicals scavenging and metal chelation assays (Fig. 6). Free radicals present in the body are found to be detrimental mainly in targeting DNA, lipids and proteins. It is essential to counterbalance and scavenge these unbound radicals by the antioxidants [70]. The Inhibitory Concentration at $50 \%\left(\mathrm{IC}_{50}\right)$ values for DPPH, SOD, nitric oxide and metal chelation were established to be $62 \mu \mathrm{g} / \mathrm{mL}, 46 \mu \mathrm{g} / \mathrm{mL}, 47$ $\mu \mathrm{g} / \mathrm{mL}$ and $52 \mu \mathrm{g} / \mathrm{mL}$ respectively. The maximum antioxidant property in a products will also have the anti-cancer property as the cancer cells have rapid growth which is triggered by the free radicals formed in the human body.

The scarcity of antioxidants preceeds to the formation of free radicals' chain(s) and leads to the damage in the cells or mutate the cells and thus the formation of tumours and thus cancer occurs. Recently, there is strong evidence of diseases like atherosclerosis and cancer associated with pathological conditions created by ROS in the cell system. Cirrhosis and rheumatoid arthritis are the degenerative diseases linked with ageing and due to the lack of antioxidants in the human body [37]. The free radicals are lipid alkyl (OO), lipid peroxide $\left(\mathrm{LO}_{2}{ }^{2-}\right)$, superoxide free radical anion $\left(\mathrm{O}_{2}{ }^{-}\right)$are oxygen-derived radicals and nonradical derivatives are hydrogen peroxide $\left(\mathrm{H}_{2} \mathrm{O}_{2}\right)$ and singlet oxygen $\left({ }^{1} \mathrm{O}_{2}\right)$; these are altogether known as ROS. Due to two vital determinants in the biological system these free radicals have been formed: 1 ) Cellular metabolism in ER (endoplasmic reticulum), oxidation, NADPH oxidase, electron transport chain in mitochondria, nitric oxide synthetase; 2) Environmental factors/ sources- transition metals, pesticides, drugs, alcohol, tobacco smoke, high temperature and radiations [71]. Thus the nanoparticles have the highest ability to scavenge the free radicals in minimum concentration. This antioxidant capacity of AgONPs leads to further studies such as the elucidation of anti-cancer property in AgONPs.

\subsection{HET- CAM test on chick embryo}


The CAM analysis is a sensitive, effortlessly viable, and inexpensive in vivo scrutiny of the antiangiogenic strategy of discrete bioactive compounds. In cancer or tumour formation the most important stage is the metastasis where the blood vessels are formed around the tumor in which the tumor cells are carried via the blood channel and it can easily locate in some other parts of the body or organ(s). This is the malignant stage of cancer where the tumor formation in various parts of the organs. In this current study aimed to inhibit or prevent the formation of blood vessels (angiogenesis) by the implementation of synthesized AgONPs and this property was elucidated in embryonated chick eggs through the test HETCAM assay. The AgONPs inhibited most of the blood vessels and inhibited the newly formed blood vessels in a varied incubation period and dose-dependent manner.

The AgONPs inhibited the formation of blood vessels at an interval of 2 hours and 18 hours (Table. 2 and

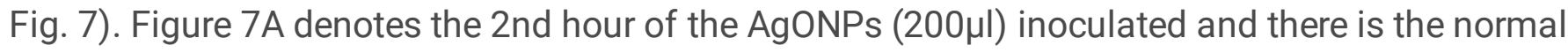
angiogenesis process. After the exposure of AgONPs (18 h) has been explicated that the inhibition of blood vessels formation and diminished the early angiogenesis (Fig. 7b). The report of Patil et al [36] was similar to the current study where the AgNPs synthesized from fungal species exhibited the antiangiogenesis at $0.1 \mu \mathrm{g}$ concentration. The NPs system have the ability to overcome the blood-brain barrier (BBB) which can be used as anti-cancer therapeutic agents. Further, these AgONPs responds to respective magnetic field and also light which paves a way to therapeutic agents in cancer treatment [72].

These types of NPs can also be used as nanocarriers in drug delivery system in the respective medicinal fields. This manifests that the AgONPs has the significant anti-angiogenic property which could easily inhibit in the tumour cells and explored as anti-cancer agents.

\section{Conclusion}

This work demonstrates the antimicrobial, antioxidant and anti-angiogenic properties in the synthesized AgONPs mediated from $A$. terreus FC36AY1. The AgONPs exhibited the highest antagonistic and antimicrobial properties in minimum concentration; this is due to the presence of medicinal properties elicited on the NPs in the extracellular enzyme matrix. The AgONPs were synthesized at $100 \mathrm{mM}$ silver nitrate concentration and the confirmation was elucidated through UV-Vis spectrum where the peak appeared in the region between $425 \mathrm{~nm}$ to $470 \mathrm{~nm}$. The SEM analysis explored the particle size ranged between $60 \mathrm{~nm}$ to $100 \mathrm{~nm}$ and the shape was in an irregular spherical shape. The functional groups present in the AgONPs are hydroxyl, alkene, alcohol and carboxyl groups with aromatic compounds, and EDX analysis confirms the residence of silver elements. Finally, the AgONPs evinced the anti-angiogenic property by the inhibition of blood vessels formation through HET-CAM analysis and this manifests that the AgONPs can be taken for further anti-cancer assessment. This is the first report where the antiangiogenesis property was explored by the AgONPs synthesized from an endophytic fungus A. terreus.

\section{Declarations}

\section{Acknowledgement}


The authors were grateful to their institutional authorities for their support and also thankful to the Department of Nanoscience, Bharathiar University, Coimbatore, India for facilitating the instruments.

Ethics approval and consent to participate Not applicable

Consent for publication Not applicable

Funding Not applicable

\section{Conflict of interest}

The authors declare that they have no conflict of interest in the publication.

Availability of data and material Not applicable

Code availability Not applicable

\section{Authors' contributions}

Vellingiri Manon Mani: Data curation, Methodology, Writing - original draft; John Kennedy Mithu Ashwin: Methodology, Formal analysis; Arockiam Jeyasundar Parimala Gnana Soundari: Data curation, Methodology, Formal analysis; Swamiappan Sathiskumar: Methodology; Ulaganathan Priyadharshini: Data curation, Methodlogy; Paramasivam Deepak: Formal analysis, Resources; Wen-chao Liu: Validation, Writing - review \& editing; Balamuralikrishnan Balasubramanian: Conceptualization, Validation, Visualization, Writing - review \& editing;

\section{Declarations}

The authors declare that they have no known competing financial interests or personal relationships that could have appeared to influence the work reported in this paper.

\section{References}

1. Li Y, Duan X, Qian Y, Yang L, Liao H (1999) Nanocrystalline silver particles: synthesis, agglomeration, and sputtering induced by electron beam. J Colloid Interface Sci 209:347-349. https://doi.org/10.1006/jcis.1998.5879

2. Merza S, Al-Attabi HD, Abbas ZM, Yusr HA (2012) Comparative study on methods for preparation of gold nanoparticles. Green Sustain Chem 02:26-28. https://doi.org/10.4236/gsc.2012.21005

3. Pulit J, Banach M, Kowalski Z (2013) Chemical reduction as the main method for obtaining nanosilver. J Comput Theor Nanosci 10:276-284. https://doi.org/10.1166/jctn.2013.2691

4. Mallick K, Witcomb MJ, Scurrell MS (2004) Polymer stabilized silver nanoparticles: a photo chemical synthesis route. J Mater Sci 39:4459-4463. https://doi.org/10.1023/b:jmsc.0000034138.80116.50 
5. Neethu S, Midhun SJ, Radhakrishnan EK, Jyothis M (2020) Surface functionalization of central venous catheter with mycofabricated silver nanoparticles and its antibiofilm activity on multidrug resistant Acinetobacter baumannii. Microbial Pathogenesis 138.

https://doi.org/10.1016/j.micpath.2019.103832

6. Kitching M, Ramani M, Marsili E (2015) Fungal biosynthesis of gold nanoparticles: mechanism and scale up. Microbial Biotechnol 8(6):904-917. doi:10.1111/1751-7915.12151

7. Shivaji S, Madhu S, Singh S (2011) Extracellular synthesis of antibacterial silver nanoparticles using psychrophilic bacteria. Process Biochem 49:830-837

8. Gade AK, Bonde P, Ingle AP, Marcato PD, Durán N, Rai MK (2008) Exploitation of Aspergillus niger for synthesis of silver nanoparticles. J Biobased Mater Bioenergy 2:1-5

9. Thakkar KN, Mhatre SS, Parikh RY (2010) Biological synthesis of metallic nanoparticles. Nanomed Nanotechnol Biol Med 6:257-262

10. Ahmad A, Mukherjee P, Senapati S, Mandal D, Khan MI, Kumar R et al (2003) Extracellular biosynthesis of silver nanoparticles using the fungus Fusarium oxysporum. Colloids Surf $B$ Biointerfaces 28:313-318

11. Kathiresan K, Manivannan S, Nabeel MA, Dhivya B (2009) Studies on silver nanoparticles synthesized by a marine fungus, Penicillium fellutanum isolated from coastal mangrove sediment. Colloids Surf B Biointerfaces 71:133-137

12. Fayaz AM, Tiwary CS, Kalaichelvan PT (2010) Venkatesan, R. Blue orange light emission from biogenic synthesized silver nanoparticles using Trichoderma viride. Colloids Surf B Biointerfaces 75:175-178

13. Ishida K, Cipriano TF, Rocha GM et al (2014) Silver nanoparticle production by the fungus Fusarium oxysporum: nanoparticle characterisation and analysis of antifungal activity against pathogenic yeasts. Mem Inst Oswaldo Cruz 109(2):220-228. doi:10.1590/0074-0276130269

14. Kaler A, Jain S, Banerjee UC (2013) Green and rapid synthesis of anti- cancerous silver nanoparticles by Saccharomyces boulardii and insight into mechanism of nanoparticle synthesis. Biomed Res Int 2013: 8

15. Manivasagan P, Venkatesan J, Senthilkumar K, Sivakumar K, Kim SK (2013) Biosynthesis antimicrobial and cytotoxic effect of silver nanoparticles using a novel Nocardiopsis sp. MBRC-1. Biomed Res Int 2013: 9

16. Balakumaran MD, Ramachandran R, Kalaicheilvan PT (2015) Exploitation of endophytic fungus, Guignardia mangiferae for extracellular synthesis of silver nanoparticles and their in vitro biological activities. Microbiol Res 178:9-17. doi:10.1016/j.micres.2015.05.009

17. Goffeau A (2008) Drug resistance: the fight against fungi. Nature 452:541-542

18. Subban K, Subramani R, Johnpaul MA (2013) novel antibacterial and antifungal phenolic compound from the endophytic fungus Pestalotiopsis mangiferae. Nat Prod Res 27:1445-1449

19. Qian Y, Yu H, He D, Yang H, Wang W, Wan X et al (2013) Biosynthesis of silver nanoparticles by the endophytic fungus Epicoccum nigrum and their activity against pathogenic fungi. Bioprocess 
Biosyst Eng 36:1613-1619. doi:10.1007/s00449-013-0937-z

20. Devi SL, Donalad AB, Joshi SR (2014) Studies on biosynthesis of antimicrobial silver nanoparticles using endophytic fungi isolated from the ethno-medicinal plant Gloriosa superba L. P Natl A Sci India B 84:1091-1099

21. Devi SL, Joshi SR (2015) Ultrastructures of silver nanoparticles biosynthesized using endophytic fungi. J Microsc Ultrastruct 3:29-37. doi:10.1016/j.jmau.2014.10.004

22. Singh D, Rathod V, Ninganagouda S, Hiremath J, Singh AK, Mathew J (2014) Optimization and Characterization of Silver Nanoparticle by Endophytic Fungi Penicillium sp. Isolated from Curcuma longa (Turmeric) and Application Studies against MDR E. coli and S. aureus. Bioinorg Chem Appl Article ID 408021:8 pages. http://dx.doi.org/10.1155/2014/408021

23. Mani VM, Soundari APG, Karthiyaini D, Preethi K (2015) Bioprospecting for endophytic fungi and their metabolites from medicinal tree Aegle marmelos in Western Ghats, India. Mycobiol 43(3):303310

24. Mani VM, Soundari APG, Tamilarasi S (2018) Determination of in vitro cytotoxicity and antiangiogenesis for a bioactive compound from Aspergillus terrus FC36AY1 isolated from Aegle marmelos around Western Ghats, India. In: InTech Open- Book: Medicinal Chemistry 13-28

25. Vellingiri MM, Soundari A J P G, Priyadarisini VB, Liu W, Balamuralikrishnan B (2020) Statistical optimization of parameters for enhanced quorum quenching metabolites produced by Streptomyces hygroscopicus AVS7. Arabian J Sci Eng Online. https://doi.org/10.1007/s13369-020-05116-y

26. Yildirim A, Mavi A, Oktay M, Kara AA, Algur OF, Bilaloglu V (2000) Comparison of antioxidant and antimicrobial activities of Tilia (Tilia argentea Desf Ex DC), Sage (Savia triloba L.), and Black Tea (Camellia sinensis) extracts. J Agric Food Chem 48(10):5030-5034

27. Parija SC, Prabhakar PK (1995) Evaluation of lacto-phenol cotton blue for wet mount preparation of feces. J Clin Microbiol 33:1019-1021

28. Doss RP, Welty RE (1995) A polymerase chain reaction-based procedure for detection of Acremonium coenophialum in tall fescue. Phytopathology 85: $913-7.7$

29. Lacap DC, Hyde KD, Liew E (2003) C. An evaluation of the fungal 'morphotype' concept based on ribosomal DNA sequences. Fungal Divers 12:53-66

30. Barry AL, Garcia F, Thrupp LD (1970) An improved single disc method for testing the antibiotic susceptibility for rapidly growing pathogens. Am J Clin Pathol 53:149-158

31. Dinis TCP, Madeira VMC, Almeida LM (1994) Action of phenolic derivates (acetoaminophen, salycilate and 5-aminosalycilate) as inhibitors of membrane lipid peroxidation and as peroxyl radical scavengers. Arch Biochem Biophy 315:161-169

32. Abeer RM, Abdel- Aziz, Monira R, Al-Othmana SA, Eifana, Mohamed A, Mahmoud B, Majrashi M (2014) Green synthesis of silver nanoparticles using Aspergillus terreus (KC462061). Digest J Nanomat Biostruct 8(3):1215-1225

33. Ashrafi SJ, Rastegar MF, Ashrafi M, Yazdian F, Pourrahim R, Suresh AK (2013) Influence of external factors on the production and morphology of biogenic silver nanocrystallites. J Nanosci 
Nanotechnol 13:2295-2301. doi:10.1166/jnn.2013.6791

34. Azmath P, Baker S, Rakshith D, Satish S (2016) Mycosynthesis of silver nanoparticles bearing antibacterial activity. Saudi Pharm J 24:140-146. doi:10.1016/j.jsps.2015.01.008

35. Balakumaran MD, Ramachandran R, Bala shanmugam P, Mukesh kumar D, Kalaichelvan PT (2016) Mycosynthesis of silver and gold nanoparticles: Optimization, characterization and antimicrobial activity against human pathogens. Microbiol Res 182:8-20

36. Brown T, Smith D (1976) The effects of silver nitrate on the growth and ultrastructure of the yeast Cryptococcus albidus. Microbios Lett 3:155-162

37. Costa- Silva LP, Oliveira JP, Keijok WJ, Silva AR, Aguiar AR, Guimarães MC C, et al (2017) Extracellular biosynthesis of silver nanoparticles using the cell-free filtrate of nematophagus fungus Duddingtonia flagans. Int J Nanomed 12:6373-6381. doi:10.2147/IJN.S137703

38. Deepak V, Kalishwaralal K, Pandian SRK, Gurunathan S (2011) An Insight into the Bacterial Biogenesis of Silver Nanoparticles, Industrial Production and Scale-up. In: Metal Nanoparticles in Microbiology. M.K. Rai N, Duran (eds), Springer, New York, pp 17-35

39. Doomsch KH, Gams W, Anderson TH (2007) Compendium of soil fungi 1- 672

40. Elamawi RM, Al-Harbi RE, Hendi AA (2018) Biosynthesis and characterization of silver nanoparticles using Trichoderma longi brachiatum and their effect on phytopathogenic fungi. Egypt $\mathrm{J}$ Biol Pest Control 28:1-28. doi:10.1186/s41938-018-0028-1

41. Emerit I (1994) Reactive oxygen species, chromosome mutation, and cancer: possible role of clastogenic factors in carcinogenesis. Free Radical Med 16:99-109

42. Fátima F, Verma SR, Pathak N, Bajpai P (2016) Extracellular mycosynthesis of silver nanoparticles and their microbicidal activity. J Glob Antimicrob Resist 7:88-92. doi:10.1016/j.jgar.2016.07.013

43. Gole A, Dash C, Ramakrishnan V et al (2001) Pepsin-gold colloid conjugates: preparation, characterization, and enzymatic activity. Langmuir 17(5):1674-1679

44. Gudikandula K, Vadapally P, Charya MAS (2017) Biogenic synthesis of silver nanoparticles from white rot fungi: their characterization and antibacterial studies. Open Nano 2:64-78. doi:10.1016/j.onano.2017.07.002

45. Guilger- Casagrande M, Lima R (2017) Synthesis of Silver Nanoparticles Mediated by Fungi: A Review. Front Bioeng Biotechnol 7:287. doi:10.3389/fbioe.2019.00287

46. Keuk-Jun K, Sung WS, Moon SK, Choi JS, Kim JG, Lee DG (2008) Antifungal effect of silver nanoparticles on dermatophytes. J Microbiol Biotechnol 18:1482-1484

47. Kim JS, Kuk E, Yu KN et al (2007) Antimicrobial effects of silver nanoparticle. Nanomed 3(1):95-101

48. Krol S, Macrez R, Docagne F, Defer J, Laurent S, Rahman M, Hajipour MJ, Kehoe PG, Mahmoudi M (2013) Therapeutic Benefits from Nanoparticles: The Potential Significance of Nanoscience in Diseases with Compromise to the Blood Brain Barrier. Chem Rev 113(3):1877-1903. https://doi.org/10.1021/cr200472g 
49. Liu F, Ooi VEC, Chang ST (1997) Free radical scavenging activities of mushroom polysaccharide extracts. Life Sci 60:763-771

50. Liu J, He F, Gunn TM, Zhao D, Roberts CB (2009) Precise seed-mediated growth and size-controlled synthesis of palladium nanoparticles using a green chemistry approach. Langmuir 25:7116-7128

51. Lohoues EEC, Trebissou JND, Aka J, Konan AML, Djinhi J, Yapi HF, Adima A (2014) Evaluation of the antioxidants content in aqueous extract of leaves of Vepris verdoorniana (Rutaceae). Int J Pharma Biosci 5(4):80-85

52. Mishra A, Kumari M, Pandey S, Chaudhry V, Gupta KC, Nautiyal CS (2014) Biocatalytic and antimicrobial activities of gold nanoparticles synthesized by Trichoderma sp. Biores Technol $166: 235-242$

53. Mishra A, Tripathy S, Wahab R, Jeong S-H, Hwang I, Yang YB et al (2011) Microbial synthesis of gold nanoparticles using the fungus Penicillium brevicompactum and their cytotoxic effects against mouse mayoblast cancer C2C12 cells. Appl Microbiol Biotechnol 92:617-630

54. Mohanpuria P, Rana NK, Yadav SK (2008) Biosynthesis of nanoparticles: technological concepts and future applications. J Nanopart Res 10: 507-517. https://doi.org/10.1007/s11051-007-9275-x

55. Morones JR, Elechiguerra JL, Camacho A, Holt K, Kouri JB, Ramírez JT, Yacaman MJ (2005) The bactericidal effect of silver nanoparticles. Nanotechnol 16:2346-2353. https://doi.org/10.1088/0957-4484/16/10/059

56. Musarrat J, Dwivedi S, Singh BR, Al-Khedhairy AA, Naqvi AAA (2010) Production of antimicrobial silver nanoparticles in water extracts of the fungus Amylomyces rouxii strain KSU-09. Biores Technol 101:8772-8776

57. Nayak RR, Pradhan N, Behera D, Pradhan KM, Mishra S, Sukla LB, Mishra BK (2011) Green synthesis of silver nanoparticle by Penicillium purpurogenum NPMF: the process and optimization. J Nanopart Res 13(8):3129-3137

58. Ninganagouda S, Rathod V, Jyoti H, Singh D, Prema K, Manzoor- Ul- Haq (2013) Extracellular biosynthesis of silver nanoparticles using Aspergillus flavus and their antimicrobial activity against gram negative MDR strains. Int J Pharma Bio Sci 4(2):222-229

59. Patel RP, Moellering D, Murphy-Ullrich J, Jo H, Beckman JS, Darley-Usmar VM (2000) Cell signaling by reactive nitrogen and oxygenspecies in atherosclerosis. Free Radical Biol Med 28(12):1780-1794

60. Patil HBV, Nithin KS, Sachhidanand S, Siddaramaiah, Chandrashekar KT, Sathish Kumar BY (2019) Mycofabrication of bioactive silver nanoparticle: Photo catalysed synthesis and characterization to attest its augmented bio-efficacy. Arab J Chem 12:4596-4611

61. Phanjom P, Ahmed G (2017) Effect of different physicochemical conditions on the synthesis of silver nanoparticles using fungal cell filtrate of Aspergillus oryzae (MTCC No. 1846) and their antibacterial effects. Adv Nat Sci Nanosci Nanotechnol 8:1-13. doi:10.1088/2043-6254/aa92bc

62. Qidwai A, Pandey A, Kumar R, Shukla SK, Dikshit A (2018) Advances in biogenic nanoparticles and the mechanisms of antimicrobial effects. Indian J Pharm Sci 80:592-603. doi:10.4172/pharmaceutical-sciences. 1000398 
63. Ravindran C, Naveenan T (2011) Adaptation of marine derived fungus Chaetomium globosum (NIOCC 36) to alkaline stress using antioxidant properties. Proc Biochem 46:847-857

64. Richards RME, Odelola HA, Anderson B (1984) Effect of silver on whole cells and spheroplasts of a silver resistant Pseudomonas aeruginosa. Microbios 39:151-157

65. Sadowski Z, Maliszewska HI, Polowczyk I, Kozlecki T, Grochowalska B (2008) Biosynthesis of colloidal-silver particles using microorganisms. Polish J Chem 82:377

66. Satchi- Fainaro R, Mamluk R, Wang L, Short SM, Nagy JA, Feng D, Dvorak AM, Dvorak HF, Puder M, Mukhopadhyay D, Folkman J (2008) Inhibition of vessel permeability by TNP-470 and its polymer conjugate, caplostatin. Cancer Cell 7:251-261

67. Sathiskumar S, Vanaraj S, Sabarinathan D, Preethi K (2018) Evaluation of antibacterial and antibiofilm activity of synthesized zinc-hydroxyapatite biocomposites from Labeo rohita fish scale waste. Mat Res Exp 5(2):025407

68. Sreejayan N, Rao MNA (1997) Nitric oxide scavenging by curcuminoids. J Pharm Pharmacol 49:105-107

69. Sunkar S, Nachiyar CV (2012) Biogenesis of antibacterial silver nanoparticles using the endophytic bacterium Bacillus cereus isolated from Garcinia xanthochymus. Asian Pacific J Trop Biomed 2(12):953-959

70. Thom C, Church MB (1918) Aspergillus fumigatus, A. nidulans, A. terreus n. sp. and their allies. American J Bot 5(2): 84- 104. doi:10.2307/2435130. JSTOR 2435130. http://www.mycobank.org/BioloMICS. aspx?TableKey=14682616000000063\&Rec=13878\&Fields=All

71. Vigneshwaran N, Kathe AA, Varadarajan PV, Nachane RP, Balasubramanya RH (2007) Silver-protein (core- shell) nanoparticle production using spent mushroom substrate. Langmuir 23:7113-7117

72. Xie J, Lee JY, Wang DI, Ting YP (2007) Silver nanoplates: from biological to biomimetic synthesis. ACS Nano 1:429-439

73. Yahyaei B, Pourali P (2019) One step conjugation of some chemotherapeutic drugs to the biologically produced gold nanoparticles and assessment of their anticancer effects. Sci Rep 9:10242. doi:10.1038/s41598-019-46602-0

\section{Figures}



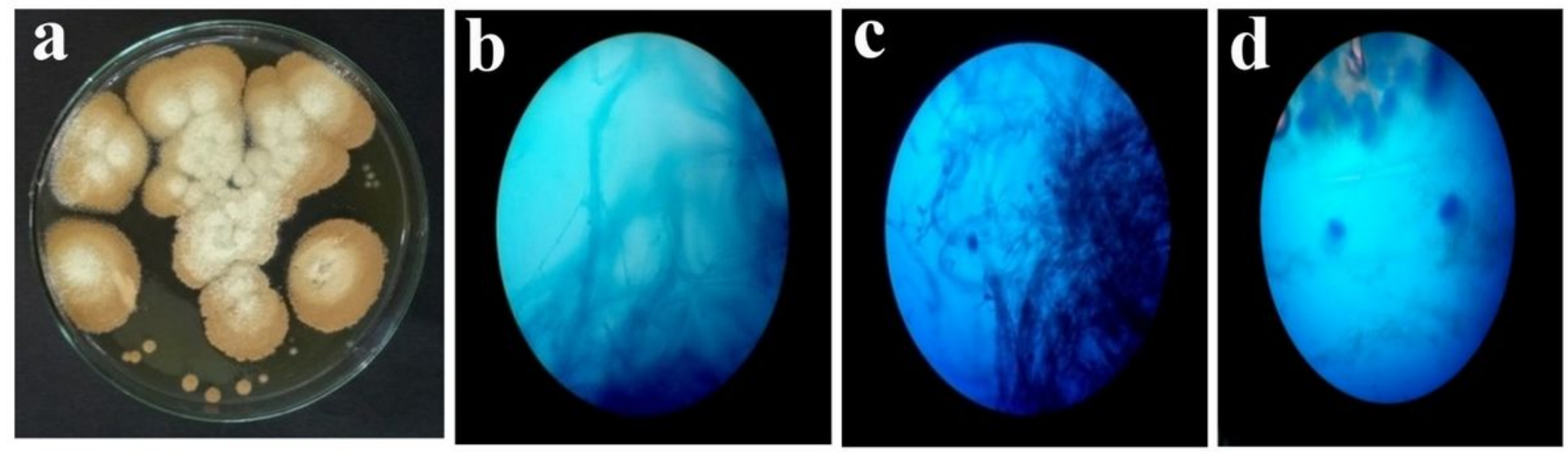

\section{Figure 1}

a) A. terreus on SDA (b) Septate Mycelia (c) Conidiophores (d) Conidia of FC36AY1.

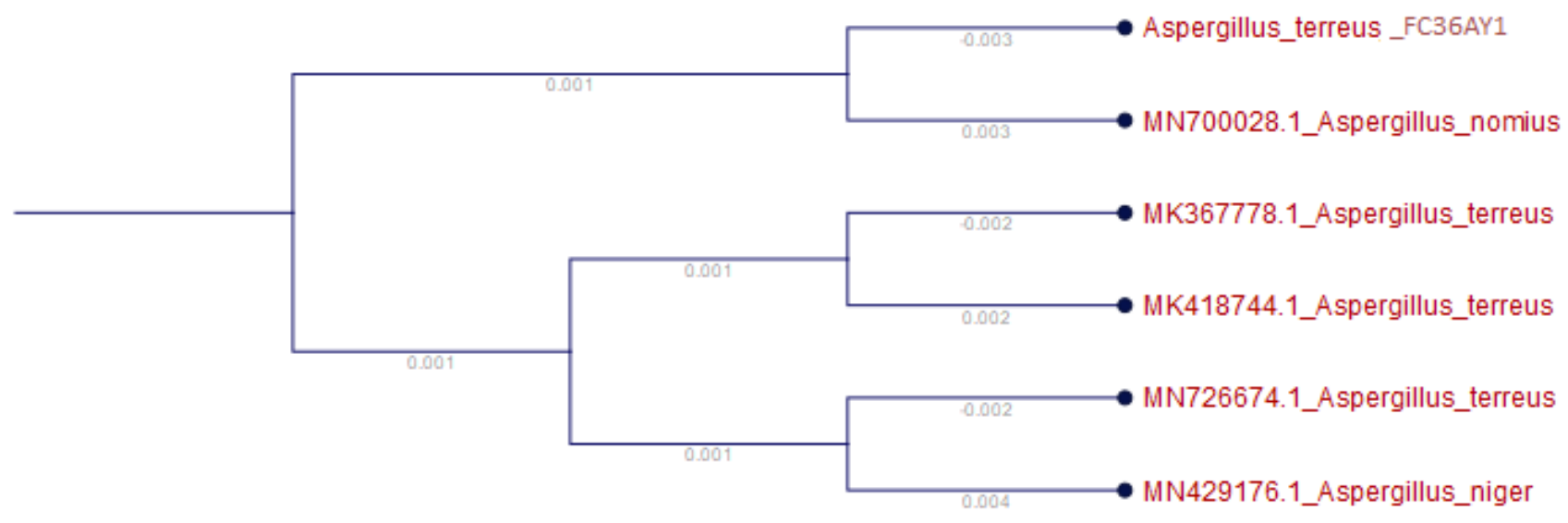

\section{Figure 2}

Phylogenetic tree based on 18S rRNA gene sequence showing the relationship between Aspergillus strains and species belonging to the genus Aspergillus. 
A

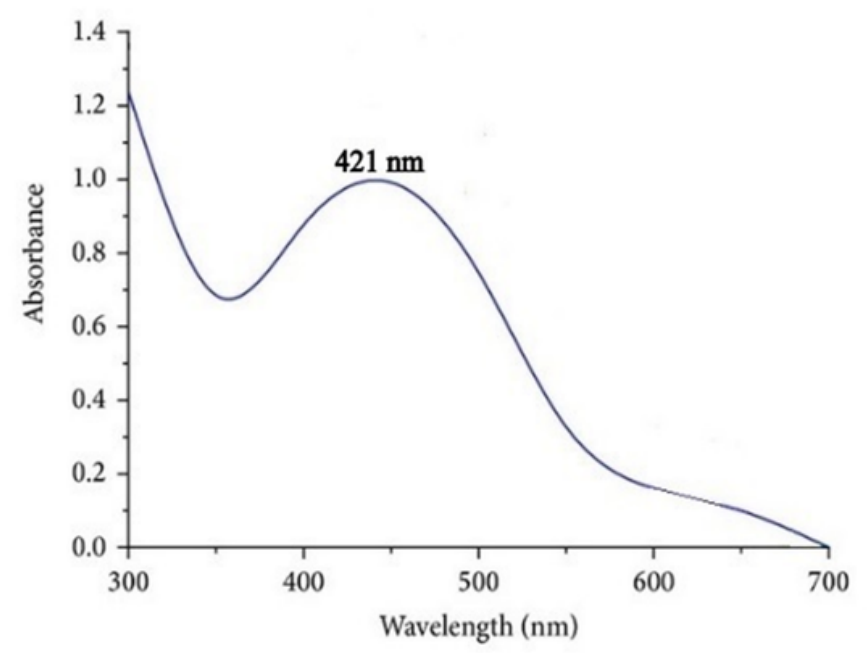

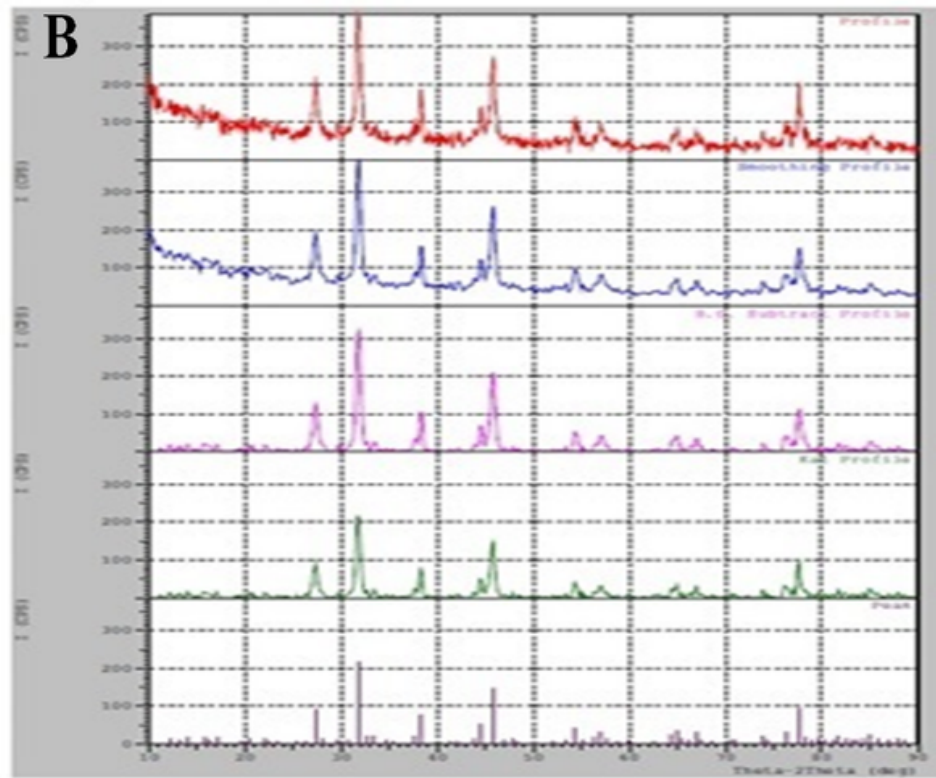

Figure 3

UV-Vis spectrum (A) and X-Ray diffraction (B) of AgONPs derived from Aspergillus terreus FC36AY1.

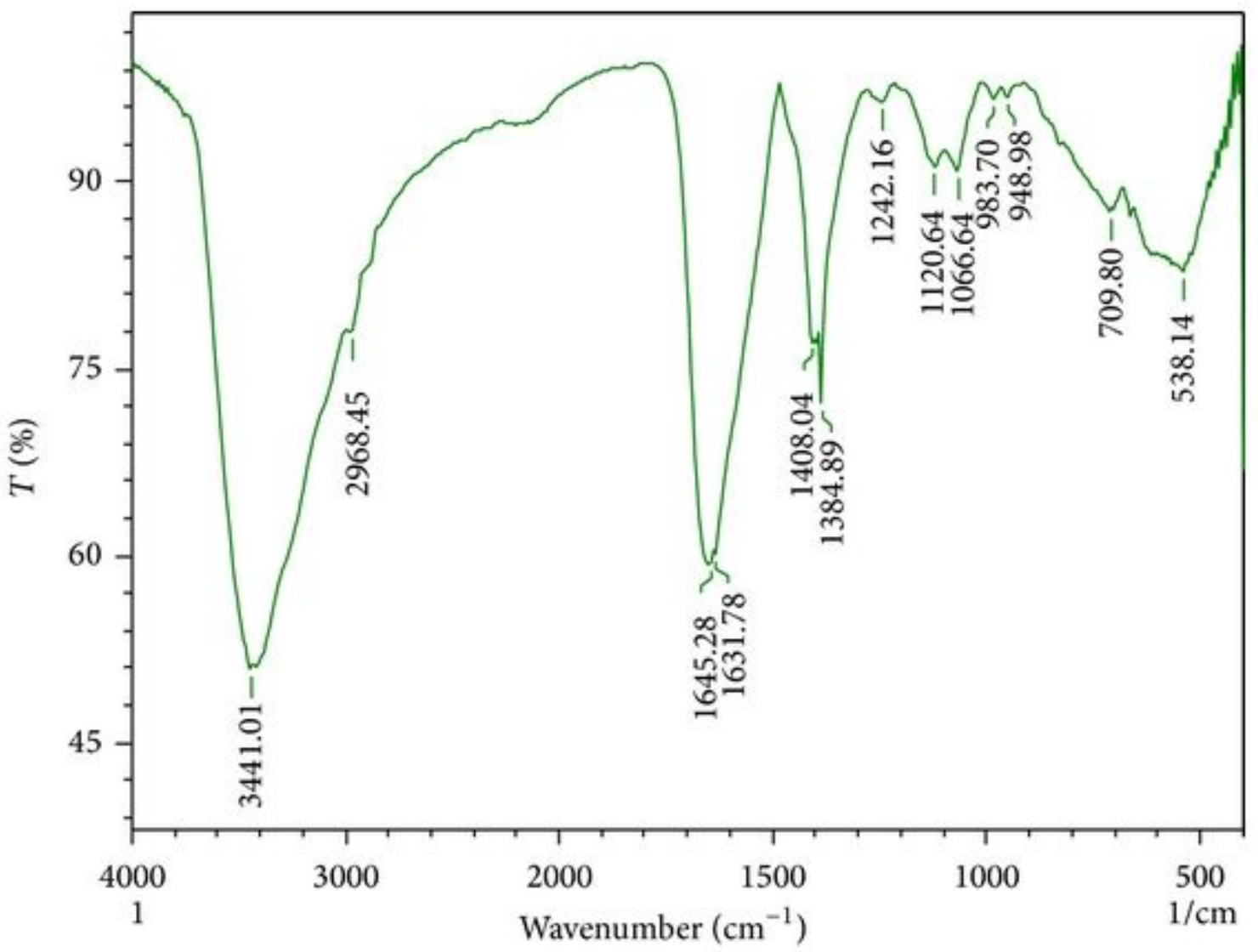

Figure 4

FT-IR spectrum of AgONPs derived from Aspergillus terreus FC36AY1 

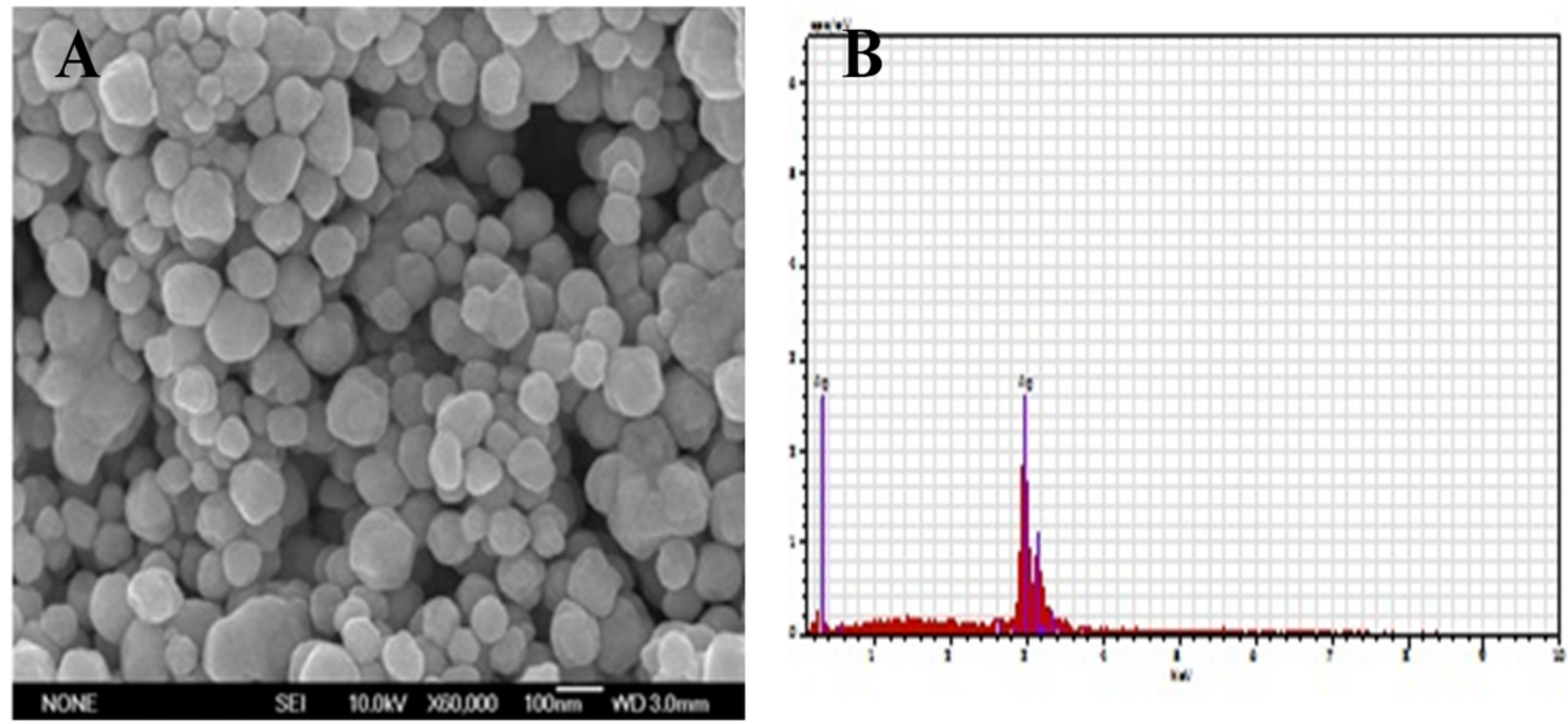

Figure 5

Scanning Electron Microscope with EDX analysis of AgONPs derived from Aspergillus terreus FC36AY1.

\section{Antioxidant activities of AgONPs}

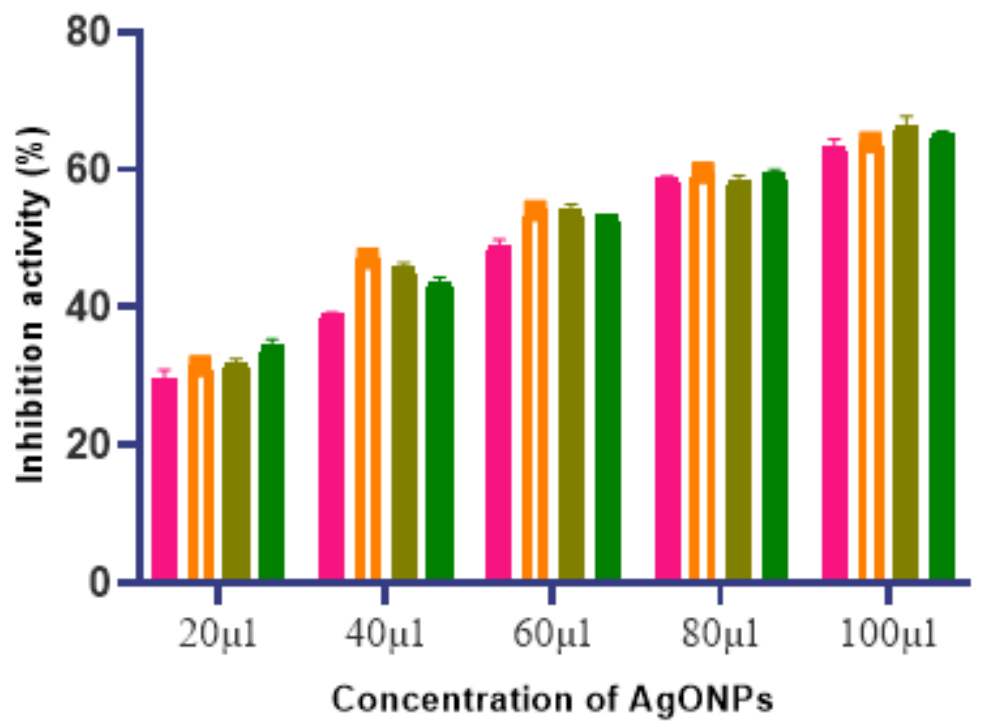

- DPPH radical scavenging activity of AgONPs

- Superoxide radical scavenging activity of AgONPs

- Nitric oxide radical scavenging activity of AgONPs

- Metal chelation activity of AgONPs

Figure 6

Antioxidant analysis for synthesized AgONPs derived from Aspergillus terreus FC36AY1 

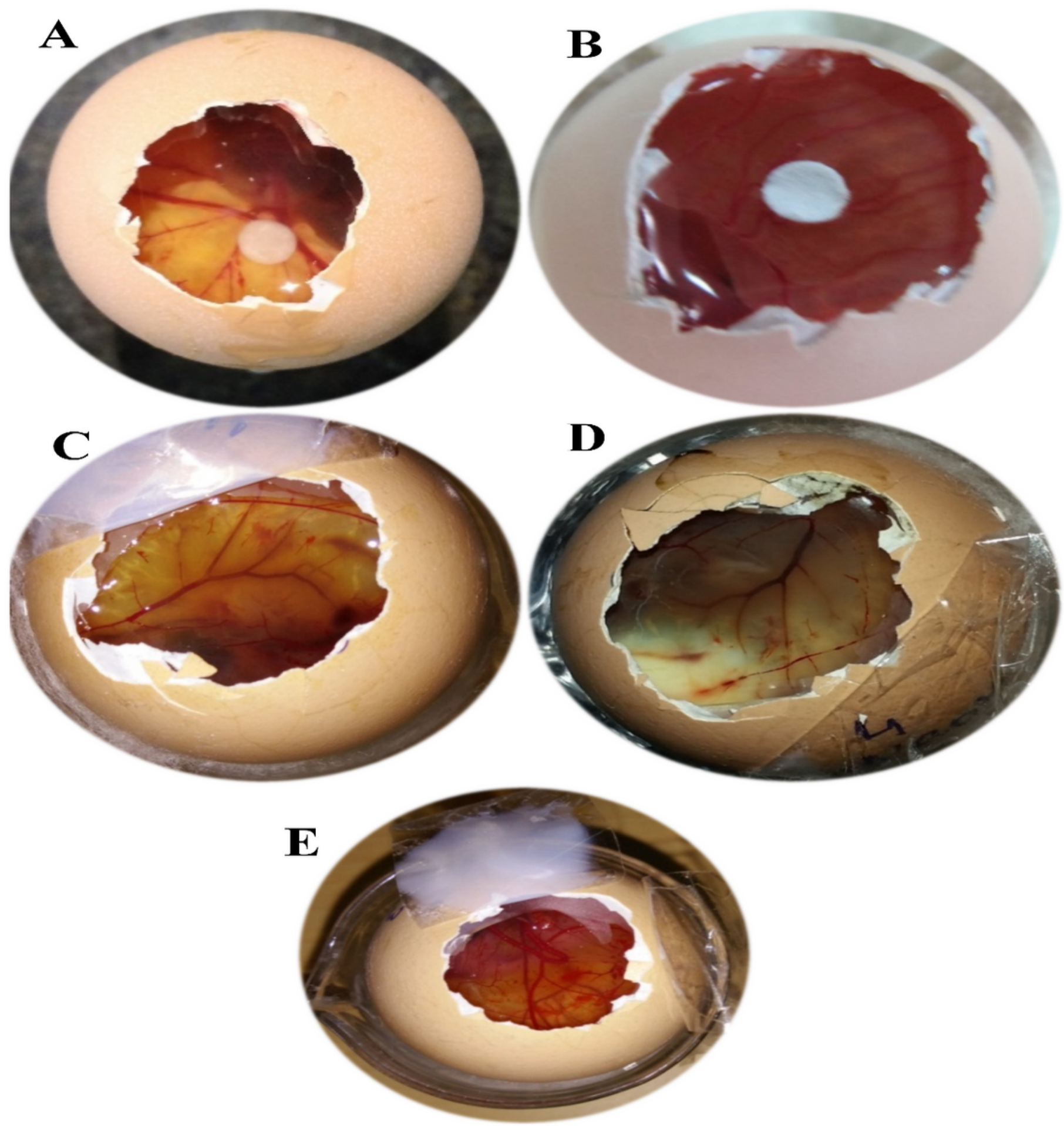

Figure 7

HET- CAM assay for anti-angiogenesis property of AgONPs at (a) $2 \mathrm{~h}$, (b) $18 \mathrm{~h}$; positive control $\mathrm{NaOH}$ (c) 2 h, (d) $18 \mathrm{~h}$ and control (e).

\section{Supplementary Files}


This is a list of supplementary files associated with this preprint. Click to download.

- GraphicalAbstract.tif

- SupplementaryTables.docx 